\title{
A pesquisa em educação ambiental: perspectivas e enfrentamentos
}

\author{
Environmental education research: perspectives and confrontations
}

\section{Investigación en educación ambiental: perspectivas y confrontaciones}

\begin{abstract}
Resumo
Isabel Cristina de Moura Carvalho ${ }^{1}$

Este artigo registra as reflexões que apresentei na mesa redonda Pesquisa em EA nos 10 anos de EPEA, no X EPEA, realizado na Universidade Federal de Sergipe, na cidade de Aracaju, de 01 a 04 de setembro de $2019^{2}$. A proposta da mesa foi realizar um balanço da educação ambiental e apontar os principais desafios e enfrentamentos da EA no cenário atual. Assim como minha fala, este artigo se organiza em três tempos. Inicio com um balanço da EA na primeira década do século XXI, trazendo dados selecionados de uma pesquisa sobre o estado da arte da produção científica em EA, da qual participei com Carmen Farias/UFRPE e Marcelo Borges/UFSC, publicada em um periódico internacional de $\mathrm{EA}^{3}$. Na segunda parte do artigo, me dedico a uma contextualização do clima social que vivíamos no Brasil quando se realizou o X EPEA, e os principais desafios que consideramos naquela conjuntura. Na terceira parte, identifico brevemente o que me parecem os principais enfrentamentos da EA que podem nos fortalecer para a resistência criativa e a resiliência que o atual momento exige.
\end{abstract}

Palavras-chave: Educação Ambiental. Pesquisa em Educação Ambiental. Perspectivas da Educação Ambiental.

\begin{abstract}
This article records the reflections I presented at the round table Research in EA in the 10 years of EPEA, at the $\mathrm{X}$ EPEA, held at the Federal University of Sergipe, in the city of Aracaju, from 01 to 04 September 2019. The table's proposal was to take stock of environmental education and point out the main challenges and confrontations of EA in the current scenario. Like my speech, this article is organized in three stages. I start with an assessment of EA in the first decade of the 21st century, bringing selected data from a research on the state of the art of scientific production in EA, in which I participated with Carmen Farias / UFRPE and Marcelo Borges / UFSC, published in an international journal of AND THE. In the second part of the article, I dedicate myself to contextualizing the social climate we lived in Brazil when the X EPEA was held, and the main challenges we considered at that juncture. In the third part, I briefly identify what I think are the main challenges facing EA that can strengthen us for the creative resistance and resilience that the current moment demands.
\end{abstract}

Keywords: Environmental Education. Environmental Education research. Perspectives on Environmental Education.

\section{Resumen}

Este artículo registra las reflexiones que presenté en la mesa redonda Investigación en EA en los 10 años de EPEA, en la X EPEA, celebrada en la Universidad Federal de Sergipe, en la ciudad de Aracaju, del 01 al 04 de septiembre de 2019. La propuesta de la mesa era hacer un balance de la educación ambiental y señalar los principales desafíos y confrontaciones de EA en el escenario actual. Al igual que mi discurso, este artículo está organizado en tres etapas. Comienzo con una evaluación de EA en la primera década del siglo XXI, con datos seleccionados de una investigación sobre el estado del arte de la producción científica en EA, en la que participé con Carmen Farias /

\footnotetext{
${ }^{1}$ Universidade Federal de São Paulo.

${ }^{2}$ A mesa se chamou A pesquisa em educação ambiental em 10 anos de EPEA: perspectivas e enfrentamentos e teve a participação dos colegas Rosa Maria Feiteiro Cavalari (UNESP) e Rosilea Oliveira de Almeida (UFBA).

${ }^{3}$ Esta pesquisa foi publicada em versão integral no Journal Environmental Education Research. Special Issue on Environmental Education Research (FARIAS; CARVALHO; BORGES, 2018) e pode ser acessada em <http://www.tandfonline.com/doi/full/10.1080/13504622.2017.1326018>.
} 
UFRPE y Marcelo Borges / UFSC, publicado en una revista internacional de EA. En la segunda parte del artículo, me dedico a contextualizar el clima social que vivíamos en Brasil cuando se llevó a cabo la X EPEA, y los principales desafíos que consideramos en ese momento. En la tercera parte, identifico brevemente cuáles considero que son los principales desafíos que enfrenta EA que pueden fortalecernos para la resistencia creativa y la resistencia que exige el momento actual.

Palabras clave: Educación Ambiental. Investigación en Educación Ambiental. Perspectivas sobre Educación Ambiental.

\section{Introdução}

Este artigo registra as reflexões que apresentei na mesa redonda Pesquisa em EA nos 10 anos de EPEA, no X EPEA, realizado na Universidade Federal de Sergipe, na cidade de Aracaju, de 01 a 04 de setembro de $2019^{4}$. A proposta da mesa foi realizar um balanço da educação ambiental e apontar os principais desafios e enfrentamentos da EA no cenário atual. Assim como minha fala, este artigo se organiza em três tempos. Inicio com um balanço da EA na primeira década do século XXI, trazendo dados selecionados de uma pesquisa sobre o estado da arte da produção científica em EA, da qual participei com Carmen Farias/UFRPE e Marcelo Borges/UFSC, publicada em um periódico internacional de $\mathrm{EA}^{5}$. Na segunda parte do artigo, me dedico a uma contextualização do clima social que vivíamos no Brasil quando se realizou o X EPEA, e os principais desafios que consideramos naquela conjuntura. Na terceira parte, identifico brevemente o que me parecem os principais enfrentamentos da EA que podem nos fortalecer para a resistência criativa e a resiliência que o atual momento exige.

\section{Balanço da EA na primeira década dos anos 2000}

Os dados aqui apresentados são, como mencionei na introdução, uma seleção dos principais resultados da pesquisa que realizei com Carmen Farias (UFRPE) e Marcelo Gules Borges (UFSC), sobre a produção em pesquisa em Educação Ambiental (EA). A pesquisa se intitula: Uma década de pesquisa em educação ambiental no Brasil. Percursos e tendências desde três eventos científicos nacionais: ANPEd, ANPPAS e EPEA e avaliou a produção em EA nos três eventos científicos mencionados, no período de 2001 a 2012. Apresento, aqui, as principais tabelas e sintetizo os dados, cuja versão integral pode ser consultada no Environmental Education Research (FARIAS; CARVALHO; BORGES, 2018), razão pela qual as tabelas estão em inglês.

Dos três eventos científicos, cobrimos os seguintes períodos: as Reuniões Anuais da Associação Nacional de Pesquisa e Pós-Graduação em Educação, ANPEd, de 2003 a 2013; as Reuniões Nacionais da Associação Nacional de Pesquisa e Pós-Graduação em Ambiente e Sociedade, ANPPAS, de 2002 a 2012; e os Encontros de Pesquisa em Educação Ambiental, EPEAs, de 2001 a 2011. A distribuição dos eventos por ano está sintetizada na Tabela 1.

Tabela 1 - Eventos Científicos entre 2001 e 2012 


\begin{tabular}{|c|c|c|c|}
\hline Year & ANPEd & ANPPAS & EPEA \\
\hline 2001 & & & 1st Meeting \\
\hline 2002 & & 1st Meeting & \\
\hline 2003 & (EE GT) - 25th Meeting & & 2nd Meeting \\
\hline 2004 & (EE GT) - 27th Meeting & 2nd Meeting & \\
\hline 2005 & (EE GT) - 28th Meeting & & 3rd Meeting \\
\hline 2006 & (EE GT) - 29th Meeting & 3rd Meeting & \\
\hline 2007 & (EE GT) - 30th Meeting & & 4th Meeting \\
\hline 2008 & (EE GT) - 31st Meeting & 4th Meeting & \\
\hline 2009 & (EE GT) - 32nd Meeting & & 5th Meeting \\
\hline 2010 & (EE GT) - 33rd Meeting & 5th Meeting & \\
\hline 2011 & (EE GT) - 34th Meeting & & 6th Meeting \\
\hline 2012 & (EE GT) - 35th Meeting & 6th Meeting & \\
\hline
\end{tabular}

Quanto aos trabalhos publicados nos anais desses eventos, consideramos, na Tabela 02, os seguintes eventos e Grupos de Trabalho: na ANPED, consideramos o Grupo de Trabalho em Educação Ambiental, GT 22, e identificamos uma média de treze trabalhos apresentados para cada edição do evento. Na ANPPAS, consideramos o Grupo de Trabalho denominado Ambiente, Educação e Sociedade, totalizando dezenove trabalhos apresentados em cada edição do evento. Para o EPEA, que é um evento inteiramente dedicado à EA, consideramos todos os trabalhos apresentados, o que nos levou a uma média de 81 trabalhos para cada edição do evento.

Tabela 2 - Artigos publicados em anais de conferências (2001-2013)

\begin{tabular}{lccc}
\hline Year & EPEA & ANPPAS & ANPEd \\
\hline 2001 & 78 & 11 & \\
2002 & & & 12 \\
2003 & 72 & 23 & 13 \\
2004 & & & 12 \\
2005 & 73 & 16 & 13 \\
2006 & & & 12 \\
2007 & 87 & 20 & 12 \\
2008 & & & 5 \\
2009 & 90 & 28 & 21 \\
2010 & & & 18 \\
2011 & 88 & 17 & 17 \\
2012 & & & 7 \\
2013 & & 115 & 142 \\
Total & 488 & & \\
\hline
\end{tabular}

Fonte: FARIAS; CARVALHO; BORGES, 2018

Quanto à titulação acadêmica e ao sexo dos autores dos trabalhos apresentados, encontramos, na Tabela 3, 70\% de autoras, sendo 48\% doutoras ou doutorandas e 30\% mestres ou mestrandas. Esse resultado indica uma forte presença do feminino no universo da pesquisa em educação e, entre as autoras, a predominância de doutoras ou doutorandas. A predominância de mulheres confirma uma realidade do campo da educação e também uma tendência presente nas ciências humanas em geral, embora aí a predominância feminina não seja, provavelmente, tão alta quanto na educação.

Tabela 3 - Perfil dos autores/as conforme titulação acadêmica e gênero 


\begin{tabular}{lrrrr}
\hline Degree & Female & Male & & $\%$ \\
\hline PhD & 250 & 117 & 367 & 49 \\
M.A. & 199 & 68 & 267 & 36 \\
Undergrad & 37 & 19 & 56 & 8 \\
Special & 15 & 4 & 19 & 3 \\
NI & 23 & 13 & 36 & 5 \\
Total & 524 & 221 & 745 & 100 \\
\% & 70 & 30 & 100 & \\
\hline
\end{tabular}

Fonte: FARIAS; CARVALHO; BORGES, 2018

Quanto à distribuição dos trabalhos por região do Brasil, encontramos, na Tabela 4, uma predominância das regiões Sudeste $(65 \%)$ e Sul (17\%). As regiões Norte, Nordeste e CentroOeste somam, juntas, $18 \%$ do total dos trabalhos publicados nos eventos. Esse resultado corrobora com dados já conhecidos (BRASIL, 2011.) sobre a desigualdade regional na oferta de universidades, formação de doutores, concentração de riqueza e oportunidades de trabalho e pesquisa, o que se reflete na produção científica no Brasil.

Tabela 4 - Número de artigos por região de origem

\begin{tabular}{lccccc}
\hline Region & EPEA & ANPPAS & ANPEd & Total & $\%$ \\
\hline Southeast & 322 & 62 & 97 & 481 & 65 \\
South & 84 & 19 & 25 & 128 & 17 \\
Center-West & 44 & 19 & 3 & 66 & 9 \\
Northeast & 29 & 6 & 13 & 48 & 6 \\
North & 9 & 8 & 3 & 20 & 3 \\
Abroad & 0 & 1 & 1 & 2 & 0 \\
Total & 488 & 115 & 142 & 745 & 100 \\
\hline
\end{tabular}

Fonte: FARIAS; CARVALHO; BORGES, 2018

$\mathrm{Na}$ Tabela 5 temos as cidades e os estados onde esses eventos ocorreram ao longo da década analisada.

Tabela 5 - Cidades e Estados brasileiros que sediaram as conferências

\begin{tabular}{|c|c|c|c|c|}
\hline Event & Year/City/State & & & \\
\hline \multirow[t]{2}{*}{ ANPEd } & 2003 & 2004-2010 & 2011 & 2012 \\
\hline & $\begin{array}{l}\text { Poços de Caldas/Minas } \\
\text { Gerais (Southeast) }\end{array}$ & $\begin{array}{l}\text { Caxambu/Minas Gerais } \\
\text { (Southeast) }\end{array}$ & $\begin{array}{l}\text { Natal/Rio Grande do Norte } \\
\text { (Northeast) }\end{array}$ & $\begin{array}{l}\text { Porto de Galinhas/Per- } \\
\text { nambuco (Northeast) }\end{array}$ \\
\hline \multirow[t]{2}{*}{ ANPPAS } & 2002 and 2004 & 2006 e 2008 & 2010 & 2012 \\
\hline & $\begin{array}{l}\text { Indaiatuba/Säo Paulo } \\
\text { (Southeast) }\end{array}$ & $\begin{array}{l}\text { Brasilia/Distrito Federal } \\
\text { (Center-West) }\end{array}$ & $\begin{array}{l}\text { Florianópolis/Santa Catari- } \\
\text { na (South) }\end{array}$ & Belém/Pará (North) \\
\hline \multirow[t]{2}{*}{ EPEA } & 2001 and 2007 & 2003 and 2009 & 2005 and 2011 & \\
\hline & $\begin{array}{l}\text { Rio Claro/Säo Paulo } \\
\text { (Southeast) }\end{array}$ & $\begin{array}{l}\text { Säo Carlos/Săo Paulo } \\
\text { (Southeast) }\end{array}$ & $\begin{array}{l}\text { Ribeirão Preto/São Paulo } \\
\text { (Southeast) }\end{array}$ & \\
\hline
\end{tabular}

Fonte: FARIAS; CARVALHO; BORGES, 2018

Quanto às Instituições de Educação Superior (IES), encontramos (Tabela 6) a produção científica concentrada em $80 \%$ nas IES públicas, sendo que as IES privadas contam com o menor percentual (12\%) da produção científica, seguidas de outras instituições $(8 \%)$. 
Tabela 6 - Produção científica conforme afiliação institucional

\begin{tabular}{lccccc}
\hline Type of institution & EPEA & ANPPAS & ANPEd & Total & $\%$ \\
\hline Public HEl $^{3}$ & 391 & 99 & 104 & 594 & 80 \\
Private HEl $^{3}$ & 55 & 9 & 29 & 93 & 12 \\
Others & 42 & 7 & 9 & 58 & 8 \\
Total & 488 & 115 & 38 & 745 & 100 \\
\hline
\end{tabular}

aHigher Education Institutions (HE).

Fonte: FARIAS; CARVALHO; BORGES, 2018

Quanto aos temas abordados nos trabalhos, identificamos a educação ambiental no ensino formal e a preocupação com a formação de professores ocupando o centro do debate, com o maior percentual agregado (educação formal + formação professores $=33 \%$ ), como podemos observar na Tabela 7.

Tabela 7 - Número de artigos segundo as temáticas abordadas

\begin{tabular}{lcccc}
\hline Subject categories & EPEA & ANPPAS & ANPEd & Total \\
\hline EE in formal education & 113 & 14 & 26 & 153 \\
EE fundamentals & 83 & 20 & 39 & 142 \\
EE in the professional training of teachers & 59 & 15 & 19 & 93 \\
The meanings of EE & 66 & 10 & 15 & 91 \\
EE in environmental management & 55 & 11 & 4 & 70 \\
Public and/or communitarian EE & 36 & 20 & 10 & 66 \\
EE in environmental debates & 26 & 11 & 9 & 46 \\
EE in the media, arts, and other cultural channels & 27 & 3 & 10 & 40 \\
EE and subjectivity & 13 & 3 & 6 & 22 \\
Public policies for EE & 7 & 8 & 4 & 19 \\
Others & 3 & 0 & 0 & 3 \\
Total & 488 & 115 & 142 & 745 \\
\hline
\end{tabular}

Fonte: FARIAS; CARVALHO; BORGES, 2018

Quanto a uma síntese dos resultados, podemos destacar que há predominância das mulheres como autoras dos trabalhos em todos os níveis de titulação; há predominância do grau de doutor entre os autores/as dos trabalhos publicados; ocorre maior concentração da produção científica nas IES das Regiões Sudeste e Sul do Brasil, segundo análise da procedência dos trabalhos. Esses resultados indicam que as características da EA como subárea da educação seguem as tendências da grande área da educação, no Brasil. Assim, podemos afirmar que a pesquisa em EA, com suas especificidades, é parte orgânica e traz em si as marcas históricosociais atinentes ao desenvolvimento da pesquisa em educação e do sistema de Pós-Graduação no Brasil.

A segunda década dos anos 2000, mais precisamente, é o período que compreende desde 2012, quando nosso estudo terminou, até o ano de publicação deste artigo, 2020, que ainda está por ser analisado. Nosso banco de dados segue sendo alimentado, sob coordenação da professora Carmen Farias, no Programa de Pós-Graduação em Ensino de Ciências, na UFRPE. Esse banco de dados alimentou a dissertação de mestrado de Cristiana Marinho da Costa, sob orientação de Carmen Farias, defendida em 2019, intitulada: A formação de professores na área de educação ambiental: tendências da produção científica em eventos nacionais. 
Uma iniciativa importante, nesse domínio, é o projeto coordenado pelos professores Luiz Marcelo de Carvalho, na UNESP de Rio Claro, e Jorge Megid Neto, na UNICAMP, denominado EArte: Estado da Arte da Pesquisa em Educação Ambiental ${ }^{6}$. Esse projeto inclui o Banco de Teses e Dissertações Brasileiras em Educação Ambiental, concluídas no período de 1981 a 2016, e pretende alimentar esse banco até o presente. O objetivo é constituir um acervo robusto da produção acadêmica e científica, dissertações e teses, produzidas no Brasil sobre Educação Ambiental, com livre acesso para os pesquisadores em educação e ciências ambientais. Desse modo, o projeto pretende subsidiar e promover estudos sobre o estado da arte da pesquisa em educação ambiental, a partir de diferentes focos e abordagens a serem definidos pelos pesquisadores.

Uma vez feito o balanço de uma década da produção científica em EA, passamos a considerar outros desafios da EA, que incluem a pesquisa mas não se limitam a ela. Como vimos, na primeira década dos anos 2000 constata-se um crescimento da produção científica em EA no Brasil, o que é um sinal positivo do interesse acadêmico e desenvolvimento dessa área como tema de interesse científico. Contudo, ainda temos muitos outros enfrentamentos que devem influir nas tendências da produção científica para a segunda década dos anos 2000 . Por isso, a partir do próximo tópico, passo a considerar os desafios e enfrentamentos do cenário atual, quando se realizou o X EPEA.

\title{
3 Desafios e enfrentamentos: o inferno dos vivos
}

\begin{abstract}
O inferno dos vivos não é algo que será. Se existe, já está aqui, o inferno no qual vivemos todos os dias, que formamos estando juntos. Existem duas maneiras de não sofrer: a primeira é aceitar o inferno e fazer parte dele até o ponto de deixar de percebê-lo. A segunda é arriscada e exige atenção e aprendizagem contínuas: tentar saber reconhecer quem e o que, no meio do inferno, não é inferno e preservá-lo, e abrir espaço (CALVINO, 1999, p.150).
\end{abstract}

É preciso dizer que as conjunturas políticas e econômicas do Brasil são muito dinâmicas e instáveis. Apesar do imaginário idílico difuso que, como na música, alimenta a ilusão de que somos um país abençoado por Deus e bonito por natureza, vivemos uma imensa desigualdade social, marcada, diariamente, por nossa herança escravagista e patrimonialista. Temos uma história pós-colonial, marcada por ciclos curtos de democracia seguidos por golpes e regimes autoritários.

Em novembro de 2018 vivemos uma mudança importante, com a eleição de um governo federal comprometido com a desregulamentação da economia, privatização de setores estratégicos, supressão dos investimentos em educação e pesquisa, e sucateamento dos organismos e políticas ambientais. Em 2019, educadores, ambientalistas e pesquisadores identificados com a democracia foram atingidos com os rumos da política. No que diz respeito ao meio ambiente, assistimos ao acirramento dos conflitos ambientais, sobretudo os que envolvem o uso e a propriedade da terra por povos tradicionais, bem como a desproteção dos bens naturais, facilitando sua apropriação por interesses ligados ao agronegócio.

Apenas em 2019, houve um aumento de $29,5 \%$ no desmatamento, sendo que grande parte das áreas desmatadas pertencem a áreas de proteção ambiental. No mesmo período, o Ministério da Agricultura liberou o registro de 474 agrotóxicos, batendo o recorde dos últimos anos (RAVENA, 2020). Quanto à pesquisa, conforme relatório elaborado pela Comissão de Financiamento à Pesquisa e de Política de Ciência da SBPC, os investimentos realizados pelo CNPq, em 2018, retrocederam a patamares praticados vinte anos antes. Já os investimentos

\footnotetext{
${ }^{6}$ Disponível em: <http://www.earte.net/>
} 
efetuados em instituições variadas de ciência em tecnologia pela Finep, em 2018, recuaram a patamares equivalentes aos de 2003 (SBPC, 2019; FERNANDES, 2020).

Em carta publicada em 04/02/2020, na revista Nature Ecology \& Evolution, 1.230 pesquisadores pediram uma mobilização global para restaurar a credibilidade da governança ambiental no Brasil. O manifesto sugere que o governo brasileiro seja pressionado "a inverter sua agenda destrutiva" e destaca os 03 pontos mais críticos: 1) desenvolvimento de agroindústria sustentável; 2) proteção e restauração dos ecossistemas; e 3) fortalecimento dos direitos dos povos indígenas e tradicionais ${ }^{7}$ (LEVI et al., 2020, s.p).

Quanto à educação, o MEC do novo governo tem apostado em pautas ideológicas, buscando desqualificar as universidades, os estudantes e os professores. Quanto à EA, se antes já disputávamos com dificuldade seu reconhecimento nas políticas públicas, agora se radicaliza uma política de invisibilidade, apagamento, e silenciamento da EA, como foi o caso da Base Nacional Comum Curricular estabelecida pelo MEC.

O clima que envolveu a realização do X EPEA foi, portanto, o de perplexidade e temor pelo futuro da pesquisa, da educação, da preservação dos direitos e dos bens ambientais. Ao mesmo tempo, os encontros acadêmicos, em 2019, como o EPEA, se tornaram espaços de resistência, onde o estar juntos pela educação e pelo meio ambiente revigorou as esperanças para seguir defendendo o que já conquistamos e minimizar os retrocessos. Em momentos como este, estar juntos com os colegas de diversas gerações com quem compartilhamos histórias e trajetórias é importante. Como sabemos, a solidão e o isolamento são desalentadores e diminuem a potência de ação. Diante desse cenário, algumas reflexões se impõem. O desmonte da educação e das políticas ambientais torna mais relevante ainda a necessidade do alinhamento da EA com o grande campo da educação diante dos enfrentamentos comuns.

No mês em que escrevo este artigo, janeiro de 2020, o ano mal começou e já tivemos que lidar com a declaração do secretário da cultura, em vídeo, reproduzindo parte de um discurso feito por Joseph Goebbels, ministro da Propaganda de Adolf Hitler de 1933 a 1945. O então Secretário da Cultura discursou inspirado num discurso de Goebbels, tendo ao fundo a ópera Lohengrin, de Wagner, reconhecidamente vinculada à estética nazista, e reproduzindo a estética dos pronunciamentos de Hitler no cenário que utilizou. Se alguma análise de conjuntura, alguns anos atrás, tivesse antecipado um acontecimento como esse, consideraríamos exagerado e, muitos de nós, dificilmente acreditaríamos.

Tudo isso revela a força do ódio e da intolerância como motor de uma cultura política conservadora, no Brasil e no mundo. A agressividade social, isto é, o desejo de exterminar o outro e eliminar toda a diferença, ressurge, de tempos em tempos, com mais força, mostrando como é vã a esperança de que possa ser domesticada pelo ideal civilizatório de convivência pacífica e altruísta. Desde a psicanálise, busco a compreensão desse fenômeno ${ }^{8}$.

Em 2011, escrevi sobre a teoria pulsional, numa tentativa de compreender a crise ecológica desde a perspectiva da psicanálise. Não pensei que, anos depois, voltaria a esse ensaio com o mesmo sentimento de urgência, mas, dessa vez, por um motivo menos planetário. Um observador atento à vida social e às dinâmicas pulsionais não pode estar tranquilo com o mal tempo que se forma no horizonte. Refiro-me à escalada de destrutividade e à ruptura dos vínculos sociais que ameaçam nosso futuro imediato. A autorização da violência vem desenhando um ambiente propício às múltiplas expressões de ódio, intolerância e ressentimento. Uma operação reiterada sistematicamente pela estetização de gestos, imagens e

\footnotetext{
7 O manifesto pode acessado em: <https://www.nature.com/articles/s41559-019-1093-x>, na versão online da revista Nature Ecology \& Evolution.

${ }^{8}$ Uma versão curta desse texto foi publicada no Jornal ExtraClasse, Porto Alegre, 8/10/2018. (CARVALHO, 2018).
} 
enunciados que naturalizam a aplicação direta da força e, com isso, a conversão das representações da agressividade em atos de agressividade.

Um fenômeno emblemático é o gesto político, adotado por muitos brasileiros, que faz das mãos um revólver, apontando na direção do outro. Diante de tantos sentidos que esse gesto condensa, pergunto: por que o ódio tem se mostrado um ideal de identificação tão potente? Por que as narrativas do matar, eliminar, exterminar encontram tanta recepção? O que resultará dessa idealização de um Eu solitário e contra todos que depende, para sua realização, da extinção do outro? Que quantidades de angústia e medo estariam projetando-se nessa fantasia de aniquilação do outro? Até quando se sustentará a ilusão de que a agressão, ao ser mobilizada, recairá sempre sobre o outro e nunca sobre si mesmo? (CARVALHO, 2018).

Para compreender o que Ítalo Calvino (1999, p.150) chamou de "o inferno dos vivos", vale revisitar o diálogo entre dois reconhecidos cientistas do século XX. Em 1933, Einstein convida Freud a ajudá-lo a elucidar a seguinte questão: como seria possível controlar a evolução da mente humana, de modo a torná-la à prova das psicoses do ódio e da destrutividade? A resposta de Freud dá origem ao ensaio Por que a Guerra? O contexto desse diálogo era o período entre guerras e a ascensão do Nazismo que, poucos anos depois, forçaria ambos a deixarem seus países.

Em sua resposta a Einstein, Freud lembra que a civilização está longe de ser uma conquista estável. O laço social se configura na tensão permanente entre vida e morte, agressividade e amor, destruição e união. Essas forças, embora opostas, operam sempre fusionadas e o risco está, justamente, em sua separação, isto é, na predominância de apenas uma delas e na extinção da outra. Assim, se o desejo de aderir à guerra é efeito da pulsão destrutiva, a recomendação mais evidente seria contrapor-lhe sua força antagonista, a pulsão de vida. Freud conclui afirmando que tudo o que favorece o estreitamento dos vínculos emocionais entre os seres humanos deve atuar contra a Guerra.

A convivência pacífica, para Freud, só se torna possível pela ação das forças agregadoras da pulsão de vida que, ao vincular os sujeitos, pelo laço amoroso, orienta a força agressiva para o debate e a criação no plano das ideias, das artes e da vida institucional pacífica. No sentido oposto, a predominância da agressividade conduz a uma espiral destrutiva que projeta inimigos em cada um que se aproxima e toma a alteridade como ameaça iminente à integridade do Eu. Um caminho perigoso que encontra na ilusão autoritária a esperança de livrar-se de suas próprias angústias, alienando-se de si mesmo numa figura de mando, rude e punitiva.

Voltar a Freud faz a pergunta inicial ganhar nova profundidade: se o desejo de aderir às performances e narrativas do ódio é um efeito da pulsão destrutiva, quais seriam, hoje, as forças antagonistas que poderíamos mobilizar? Que imagens, gestos, enunciados, discursos e narrativas de um mundo amigável à vida, em sua pluralidade, podemos acionar para combater ativamente o ódio e a escalada de violência em curso? Nosso desafio não é menor do que o de Einstein, Freud e seus contemporâneos. Mas, sobretudo, em momentos de crise, o que conta é não renunciar aos ideais e valores pelos quais vale a pena viver.

\section{Resistências, Resiliências e Revisões críticas: notas sobre como sobreviver em tempos hostis}

No ano de 2019, participei de vários encontros de EA, além do X EPEA. Em todos eles, falando para e com educadores, me deparei com sentimentos de medo, desalento, preocupação, relatos de colegas em profunda tristeza e decepção. Ao final de minhas falas, a mesma pergunta se repetiu em todas as ocasiões: o que fazer para sobreviver aos tempos hostis? Eu tampouco tenho uma resposta salvadora. Não sejamos tão onipotentes, acreditando que existiria uma. Contudo, há algumas reflexões que trouxe para o EPEA, fruto desse ano de encontros com 
educadores, que pode, talvez, ajudar a pensarmos juntos desde uma revisão crítica da trajetória da EA nas últimas décadas.

\subsection{Desacomodar a crítica, o conceito naturalizado pela EA crítica}

Quanto ao campo específico da EA, seria interessante aprofundar o questionamento de algumas pautas históricas que, atualmente, tendem a se tornar, cada vez mais, extemporâneas. Uma delas é a oposição que construímos historicamente, para distinguir uma educação ambiental direcionada à mudança social em contraponto a outra, supostamente voltada apenas para a preservação da natureza. Ainda que essa oposição possa ter tido um sentido nos anos 1970, na afirmação de uma EA crítica, considero que faz algum tempo essa oposição deixou de trazer qualquer produtividade para a EA. Uma EA conservacionista não significa, necessariamente, uma EA politicamente conservadora ou alienada das urgências socioambientais.

Agências de conservação da natureza, como o ICMbio e o IBAMA, estão na mira da desregulamentação e uma aliança entre os educadores ambientais e os gestores ambientais das áreas de conservação da natureza me parece urgente. Penso que, neste momento, cabe assumir verdadeiramente o sentido da crítica como em Foucault (2006, p.180), quando ele afirma, em seu ensaio - é importante pensar? - que:

[...] a crítica consiste em desentocar o pensamento e em ensaiar a mudança; mostrar que as coisas não são tão evidentes quanto se crê, fazer de forma que isso que se aceita como vigente em si não o seja mais em si. Fazer a crítica é tornar difíceis os gestos fáceis demais. Nessas condições, a crítica — e a crítica radical - é absolutamente indispensável para qualquer transformação.

\subsection{Educação formal e transversalidade}

É dentro desse espírito de desentocar o pensamento e tornar difíceis os gestos fáceis demais que poderíamos desnaturalizar algumas de nossas certezas. Rever posicionamentos, que foram sendo naturalizados com o tempo, pode nos dar a abertura necessária para renovar a EA. Um desses acordos, que nutrimos por muito tempo, foi manter, sem grandes questionamentos, a oposição entre o sistema formal de ensino e currículo escolar e a noção de transversalidade da EA. Desde a Política Nacional de EA, passando pelo documento dos Parâmetros Curriculares, essa opção se consolidou com o estabelecimento da EA como um tema transversal.

Como já me posicionei outras vezes, considero que esse delineamento não contribuiu para a consolidação da EA no currículo e no espaço escolar, mantendo-a como preocupação marginal no sistema de formação escolar. O lugar da transversalidade instaurou o não lugar da EA. Isto é, consolidou a posição periférica da EA como projeto, atividade pontual e esporádica, sem continuidade nem centralidade no processo formativo, no currículo e na instituição escolar. Assim, penso que reconsiderar a possibilidade da EA como componente curricular deveria ser reconsiderado.

\subsection{Educação formal e não formal}

Outra dicotomia que não nos ajudou foi a que estabelecemos entre educação formal $e$ não formal nas práticas educativas. Essa distinção nos impede de integrar e compreender as diversas formas de aprendizagem e tem sido pouco produtiva para a EA. Penso que precisamos apostar na dissolução conceitual dessa oposição, compreendendo que as formas de aprender não se definem tanto pelo ambiente estrito da aprendizagem, mas por formas de mobilização 
da atenção, de aquisição de habilidades, de modos de participação em comunidades de práticas, que ocorrem tanto em ambientes formais e escolares quanto em grupos cujos aprendizados acontecem em ambientes não escolarizados.

\title{
5 Considerações finais
}

Por fim, concluo minhas reflexões sobre os desafios e enfrentamentos da EA com um poema de Wislawa Szymborsk (2011), prêmio Nobel de 1996, que se chama Escrevendo um currículo 9 .

\author{
Escrevendo um currículo - Wislawa Szymborsk \\ O que é preciso? \\ É preciso fazer um requerimento \\ e ao requerimento anexar um currículo. \\ O currículo tem que ser curto \\ mesmo que a vida seja longa. \\ Obrigatória a concisão e seleção dos fatos. \\ Trocam-se as paisagens pelos endereços \\ e a memória vacilante pelas datas imóveis. \\ De todos os amores basta o casamento, \\ e dos filhos só os nascidos.
}

Melhor quem te conhece do que o teu conhecido.

Viagens só se for para fora.

Associações a quê, mas sem por quê.

Distinções sem a razão.

Escreva como se nunca falasse consigo

e se mantivesse à distância.

Passe ao largo de cães, gatos e pássaros, de trastes empoeirados, amigos e sonhos.

Antes o preço que o valor e o título que o conteúdo.

Antes o número do sapato que aonde vai, esse por quem você se passa.

Acrescente uma foto com a orelha de fora.

O que conta é o seu formato, não o que se ouve.

O que se ouve?

O matraquear das máquinas picotando o papel.

Wislawa Szymborsk interpela, de forma genial, a falta de sentido da vida administrada de nossas sociedades. Um fenômeno que nos toca a todos, estejamos na educação ou em qualquer outra área. Embora a poeta se refira a um Curriculum Vitae, uma apresentação formal usada no mundo do trabalho, podemos pensar, também, o currículo escolar ou o nosso conhecido currículo acadêmico, como parte desse mesmo dispositivo de governo da vida.

O currículo escolar, por exemplo, é uma seleção de conteúdos que devem ser ensinados e aprendidos para que uma pessoa em formação seja certificada pela instituição escolar, como

\footnotetext{
${ }^{9}$ Wislawa Szymborska, Poemas, Companhia das Letras, São Paulo, 2011.
} 
apta para viver no mundo instituído. O Curriculo Vitae, por sua vez, é uma seleção de produções, títulos e eventos que exibimos para que nos certifique como aptos a uma certa posição no mundo organizacional.

Como nos lembra Szymborska, as razões íntimas, os amores fora do casamento, os filhos não nascidos, as datas vacilantes da memória afetiva, a vida longa ou curta demais, nada disso cabe no currículo, unidimensional como uma folha de papel. Contudo, as histórias dos vencidos, os saberes marginais, os conhecimentos locais, insistem e transbordam dessas capturas, pelos caminhos da arte, do humor, do sentimento do belo, da estética da existência, da imaginação, da reflexão atenta. Saídas criativas se tornam possíveis quando não nos deixamos morrer.

\section{Referências}

BRASIL. Ministério da Educação. Coordenação Nacional de Ensino Superior. Plano Nacional de Pós-Graduação. PNPG 2010-2020. Brasília, CAPES, 2011.

CALVINO, I. As cidades invisíveis. São Paulo: Companhia das Letras 1999.

CARVALHO, I. C. M. Natureza e cultura na psicanálise e no ideário ecológico: duas perspectivas sobre o mal-estar na cultura. Naveg@ merica, Murcia, v. 5, n.1 p. 1-11, 2010.

CARVALHO, I. C. M. Por que o ódio? Um diálogo muito atual entre Freud e Einstein. Jornal Extra Classe, Porto Alegre, 8 de outubro de 2018, sessão Palavra de Professor. Disponível em: <https://www.extraclasse.org.br/opiniao/2018/10/por-que-o-odio-um-dialogo-muito-atual-entreeisntein-e-freud/>. Acesso em: 24 mai. 2020.

COSTA, C. M. da. A formação de professores na área de educação ambiental: tendências da produção científica em eventos nacionais. 2019. Dissertação (Mestrado em Ensino de Ciências) Universidade Federal Rural de Pernambuco, Recife.

FARIAS, C. R. de O.; CARVALHO, I. C. M.; BORGES, M. G. One decade of environmental education research in Brazil: trajectories and trends in three national scientific conferences (ANPEd, ANPPAS and EPEA). Environmental Education Research, s/l, v. 24, n.10, p.1476-1489, 2018. Disponível em: <https://www.tandfonline.com/doi/full/10.1080/13504622.2017.1326018>. Acesso em: 24 mai. 2020.

FERNANDES, L. Ciência, Tecnologia e Inovação: a 'operação desmonte' e seus resistentes. Ensaio. Jornal Nexo, São Paulo, 07 de janeiro de 2020. Disponível em: $<$ https://www.nexojornal.com.br/ensaio/2020/Ci\%C3\%AAncia-Tecnologia-eInova\%C3\%A7\%C3\%A3o-a-\%E2\%80\%98opera\%C3\%A7\%C3\%A3o-desmonte\%E2\%80\%99-eseus-resistentes>. Acesso em: 24 mai. 2020.

FOUCAULT, M. Est-il donc important de penser? In: FOUCAULT, M. (Org.). Dits et écrits IV (1980-1988). Paris: Gallimard, 2006. p. 178-182.

FREUD, S. Por que a guerra? In: Obras Psicológicas Completas, Edição Standard Brasileira das Obras Completas de Sigmund Freud, vol. XXII. Rio de Janeiro: Imago, 1976 [1932], p. 235259. 
LEVIS, C.; FLORES, B.M.; MAZZOCHINI, G.G. et al. Help restore Brazil's governance of globally important ecosystem services. Nat Ecol Evol, s/1, n.4, p. 172-173, feb. 2020. Avaiable in: < https://www.nature.com/articles/s41559-019-1093-x\#citeas>. Access: 24 mai. 2020.

RAVENA, N. A política ambiental brasileira sob ataque: um palco de violência". Ensaio. Jornal Nexo, São Paulo, 11 de janeiro de 2020. Disponível em: <https://www.nexojornal.com.br/ensaio/2020/Apol\%C3\%ADtica-ambiental-brasileira-sob-ataque-um-palco-de-viol\%C3\%AAncias>. Acesso em: 24 mai. 2020.

SOCIEDADE BRASILEIRA PARA PROGRESSO DA CIÊNCIA - SBPC. A política brasileira de CT\&I. As manifestações da comunidade científica. Cadernos SBPC, São Paulo, 2019.

SZYMBORSKA, W. Poemas. São Paulo: Companhia das Letras, 2011. 